\title{
Sinopse do gênero Phacellocerina Lane, 1964 (Coleoptera, Cerambycidae, Lamiinae, Anisocerini)
}

\author{
Carlos Eduardo de Alvarenga Julio ${ }^{1,2}$
}

\begin{abstract}
Synopsis of the genus Phacellocerina Lane, 1964 (Coleoptera, Cerambycidae, Lamiinae, Anisocerini). The genus Phacellocerina Lane, 1964 and P. limosa (Bates, 1862) (type species) are redescribed; P. silvanae sp. nov. is described from Colombia (Santa Marta). A key to the species is added.
\end{abstract}

Keywords. Anisocerini; Lamiinae; Neotropical; Phacellocerina; taxonomy.

\section{INTRODUÇÃO}

O gênero Phacellocerina foi erigido por LANE (1964:181) para Phacellocera limosa Bates, 1862, descrita da Venezuela, diferenciando-o de Phacellocera Laporte, 1840 "pela fronte mais alargada para a parte inferior; pelas antenas mais curtas na fêmea; pelo terceiro artículo clavado no ápice e pelo quarto simples; pelos tubérculos laterais do protórax mais rombos; pelos tubérculos distintos e robustos do pronoto; pela escultura mais robusta dos élitros; pelas tíbias mais fortemente alargadas e pela linha curva das anteriores; pelo chanfro dorsal das tíbias médias mais distante do ápice; e pelos tarsos anteriores franjados no macho". Descreveu, ainda, Phacellocerina seclusa da Colômbia e comparou-a com $P$. limosa, diferenciando-a desta, principalmente, pela coloração do revestimento corporal.

Galileo \& Martins (1998:16) comentaram, ao revalidar o gênero Caciomorpha Thomson, 1864, que Phacellocerina "parece ser sinônimo de Caciomorpha e só após o exame de material esta sinonímia poderá ser formalizada".

Objetiva-se redescrever Phacellocerina e P. limosa e comparar o gênero com Phacellocera e Caciomorpha; descrever uma nova espécie e apresentar uma chave para identificação das espécies.

Foram examinados exemplares pertencentes à coleção do Museu Nacional, Universidade Federal do Rio de Janeiro, Rio de Janeiro (MNRJ) e diapositivos dos tipos de P. limosa e $P$. seclusa, feitos por J.S.Moure do Departamento de Zoologia, Universidade Federal do Paraná, Curitiba (DZUP), respectivamente, no Muséum National d'Histoire Naturelle, Paris (MNHN) e The Natural History Museum, Londres (BMNH).
Phacellocerina Lane, 1964

Phacellocerina Lane, 1964:181; Monné, 1994:3 (cat.); Galileo \& Martins, 1998:12,16.

Espécie-tipo: Phacellocera limosa Bates, 1862 (designação original).

Fronte plana, pontuada ou não, com os lados um pouco divergentes para a região inferior e borda inferior reta; sutura epistomal reta. Tubérculos anteníferos afastados entre si e ligeiramente projetados nos machos. Lobos oculares superiores tão distantes entre si quanto o dobro da largura de um lobo (exceto em P.silvanae sp. nov., mais próximos). Antenas, nas fêmeas, não ultrapassam o ápice elitral e nos machos, ultrapassam a partir do antenômero VI; escapo clavado, mais ou menos adelgaçado na base, mais robusto nos machos; antenômero III com intumescimento no lado interno do ápice, mais longo que o escapo e que o IV, este não-modificado; antenômeros $\mathrm{V}-\mathrm{X}$ gradualmente decrescentes em comprimento; $\mathrm{XI}$ com metade do comprimento do $\mathrm{X}$ nas fêmeas e um pouco mais longo que este nos machos.

Protórax mais largo que longo com tubérculo lateral cônico desenvolvido; pronoto com dois tubérculos látero-anteriores cônicos e um calo centro-basal manifesto; processo mesosternal ligeiramente escavado no centro. Élitros planos no centro do disco, granulados e com abundante pontuação profunda; gibosidade centro-basal mais ou menos protuberante e granulada no topo; metade apical de cada élitro com dois espessamentos oblíquos, um central e outro lateral, convergindo para a sutura, o central com dois tufos de cerdas curtas, um anterior e outro próximo à sutura; úmeros proeminentes e granulados; lados do disco aplanados e ápices arredondados. Protíbias aplanadas e gradualmente dilatadas externamente a partir da metade apical; protarsos franjados

\footnotetext{
1. Departamento de Entomologia, Museu Nacional, Universidade Federal do Rio Janeiro. Quinta da Boa Vista, São Cristóvão, 20940-040 Rio de Janeiro-RJ, Brasil. Endereço eletrônico: ceajulio@ig.com.br

2. Doutorando em Ciências Biológicas, Área de Concentração Zoologia, Instituto de Biociências, UNESP/Botucatu.
} 
nos machos. Mesotíbias com escavação externa próxima ao meio.

Urosternito V, nas fêmeas, deprimido no centro da margem distal e truncado no ápice.

Comentários. Assemelha-se a Phacellocera, proposto por LAPORTE (1840), pelos tubérculos anteníferos afastados entre si e pouco projetados; pelos tubérculos laterais do protórax cônicos e desenvolvidos; pelos élitros aplanados nos lados do disco; pela presença, nos élitros, de gibosidade centrobasal granulada no topo e espessamento apical com tufo de cerdas curtas; pelos úmeros proeminentes e granulados e pelo urosternito $\mathrm{V}$ das fêmeas deprimido no centro da margem distal e truncado no ápice. Distingue-se de Phacellocera pelo aspecto das antenas, mais curtas, nas fêmeas com comprimento subigual ao do corpo e nos machos ultrapassam o ápice elitral a partir do antenômero VI, sendo uma vez e meia mais longas que o corpo, escapo clavado, antenômero III com intumescimento no lado interno do ápice e IV não-modificado; pelo aspecto do pronoto, com dois tubérculos látero-anteriores cônicos e um calo centro-basal manifesto; pela gibosidade centro-basal dos élitros protuberantes; pelo aspecto dos espessamentos na metade apical dos élitros, oblíquos e alongados convergindo para a sutura, um central e outro lateral, o central com dois tufos de cerdas curtas; pelo aspecto das protíbias gradualmente dilatadas externamente a partir da metade apical e pela escavação externa das mesotíbias próxima ao meio. Em Phacellocera: antenas longas, ultrapassam o ápice elitral nas fêmeas a partir do antenômero VI e, nos machos, a partir do IV, sendo nestes duas vezes mais longas que o corpo, escapo piriforme, antenômero III muito levemente intumescido no ápice e IV com pêlos no lado interno; pronoto com dois pequenos espinhos manifestos próximo ao meio; gibosidade centro-basal dos élitros pouco elevada e quarto apical com dois espessamentos curtos providos de cerdas, um próximo à sutura e outro lateral; protíbias sub-retas; escavação externa das mesotíbias próxima ao ápice.

Assemelha-se a Caciomorpha proposto por THOMson (1864) pelos tubérculos laterais do protórax cônicos; pelo antenômero III intumescido no lado interno do ápice; pelo pronoto com dois tubérculos látero-anteriores e um calo centrobasal manifesto; pelos élitros planos no centro do disco e aplanados nos lados e presença de gibosidade centro-basal granulada no topo. Distingue-se de Caciomorpha pelos tubérculos anteníferos afastados entre si; pelo escapo clavado, mais ou menos adelgaçado na base; pelas antenas mais curtas, com comprimento, nas fêmeas, subigual ao do corpo e nos machos uma vez e meia mais longas; pelo aspecto dos élitros, granulados e com abundante pontuação profunda, gibosidade centro-basal protuberante e metade apical com duplo espessamento, sendo o anterior provido de tufos de cerdas e pelas protíbias gradualmente dilatadas externamente a partir da metade apical. Em Caciomorpha: tubérculos anteníferos próximos entre si; escapo robusto, piriforme, com o lado dorsal da base plano; antenas longas, nas fêmeas com até quase o dobro do comprimento do corpo e nos machos geralmente com o dobro; élitros com gibosidade centro-basal pouco desenvolvida, terço anterior provido de pontos granulados e metade apical sem irregularidades; protíbias sub-retas.

\section{Chave para as espécies de Phacellocerina}

1. Tegumento castanho; lobos oculares superiores tão distantes entre si quanto a largura de um lobo; escapo e pedicelo robustos na base, pouco adelgaçados e revestidos por densa pubescência decumbente; intumescimento do antenômero III proeminente e provido de pêlos; tufos de cerdas no espessamento apical dos élitros, discretos. COLÔMBIA (Santa Marta) (Fig. 2) P. silvanae sp. nov.

Tegumento negro; lobos oculares superiores tão distantes entre si quanto o dobro da largura de um lobo; escapo e pedicelo adelgaçados na base e recobertos por máculas de pubescência decumbente rala; intumescimento do antenômero III discreto e sem pêlos; tufos de cerdas no espessamento apical dos élitros, desenvolvidos 2

2(1). Pubescência decumbente esbranquiçada recobre a região longitudinal posterior da cabeça entre os lobos oculares superiores, toda extensão longitudinal central do pronoto entre os tubérculos láteroanteriores, e todo o escutelo; antenas das fêmeas com comprimento subigual ao do corpo. VENEZUELA, GUIANA (Fig. 1)

P. limosa (Bates, 1862)

Faixa oblíqua de pubescência decumbente ocre reveste a região atrás dos lobos oculares superiores, a área entre os tubérculos látero-anteriores do pronoto e o tubérculo lateral do protórax, e a região elitral entre a gibosidade centro-basal e o úmero, estendendo-se até, aproximadamente, o terço basal dos élitros; antenas das fêmeas atingem o meio dos élitros. COLÔMBIA .................................. seclusa Lane, 1964

\section{Phacellocerina limosa (Bates, 1862)}

(Fig. 1)

Phacellocera limosa Bates, 1862:448; Lameere, 1893:279 (distr.).

Phacellocerina limosa; Lane, 1964:181; Monné, 1994:3 (cat.); Galileo \& Martins, 1998:16.

Macho. Tegumento negro; máculas de pubescência decumbente branco-amarelada revestem a cabeça, escapo, pernas e a superfície ventral do corpo; pubescência decumbente esbranquiçada recobre a região longitudinal posterior da cabeça entre os lobos oculares superiores, toda extensão longitudinal central do pronoto entre os tubérculos láteroanteriores, e todo o escutelo.

Fronte plana, com pontuação profunda, os lados ligeiramente divergentes para a região inferior. Lobos oculares superiores tão distantes entre si quanto o dobro da largura de 

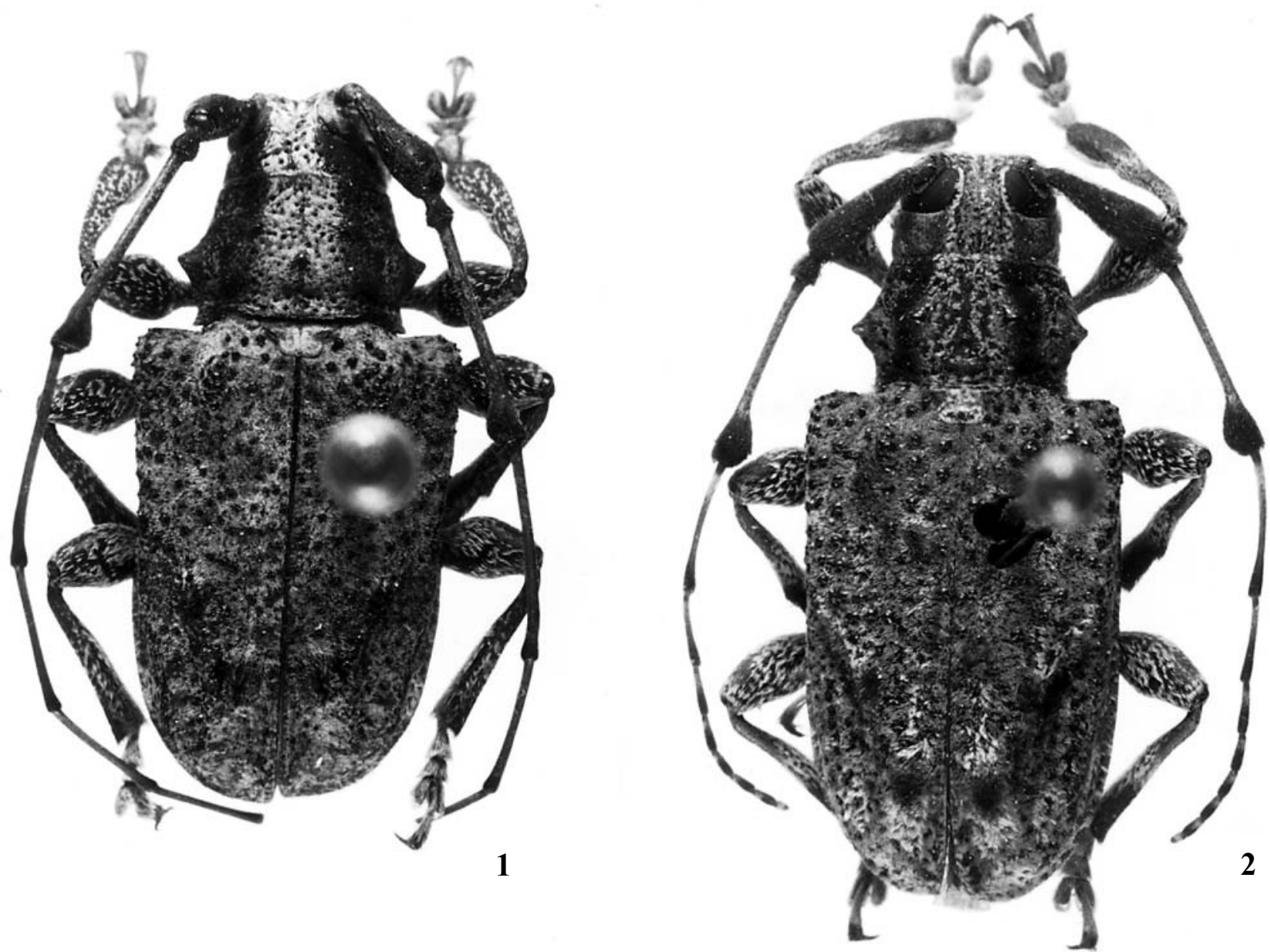

Figs. 1-2. 1, Phacellocerina limosa (Bates, 1862), macho, Caracas, Venezuela, comprimento 11,8 mm; 2, Phacellocerina silvanae sp. nov., holótipo fêmea, comprimento $12,1 \mathrm{~mm}$.

um lobo. Tubérculos anteníferos um pouco projetados. Antenas ultrapassam o ápice elitral a partir do antenômero V; escapo robusto, adelgaçado na base; antenômero III, com intumescimento discreto, mais longo que o escapo e que o IV; os demais gradualmente decrescentes em comprimento até o $\mathrm{X}$; XI um pouco mais longo que o $\mathrm{X}$.

Tubérculo lateral do protórax cônico, desenvolvido; pronoto com tubérculos látero-anteriores e calo centro-basal desenvolvidos; processo mesosternal com ligeira escavação central. Élitros recobertos por rala pubescência decumbente branco-amarelada, com densa pontuação profunda e granulados no terço basal; gibosidade centro-basal protuberante, densamente granulada; espessamentos apicais e tufos de cerdas negras desenvolvidos. Protíbias aplanadas e gradualmente dilatadas a partir da metade apical; tarsos recobertos por pubescência, os anteriores com franjas laterais negras.

Fêmea. Tubérculos anteníferos não-projetados; antenas com comprimento subigual ao do corpo; escapo mais esbelto; élitros com dois pequenos tufos de cerdas negras curtas, semelhantes ao dos espessamentos apicais, atrás das gibosidades centro-basais e próximos à sutura; urosternito $\mathrm{V}$ com depressão semi-circular centro-apical acentuada.

Dimensões $(\mathrm{mm})$, respectivamente, macho e fêmea. Comprimento total, 11,8 e 12,7; comprimento do protórax, 2,3 e 2,5; maior largura do protórax, 4,0 e 4,4; comprimento do élitro, 7,7 e 8,7 ; largura umeral, 5,1 e 5,9.

Material examinado. VENEZUELA, Caracas, macho e GUIANA, fêmea (MNRJ).

\section{Phacellocerina silvanae sp. nov.}

(Fig. 2)

Etimologia. Espécie dedicada a Silvana M. Schneider.

Fêmea. Tegumento castanho; máculas de pubescência decumbente castanho-clara recobrem a cabeça, fêmures, 
superfície ventral do corpo e formam anel central nas tíbias; pubescência decumbente esbranquiçada reveste região longitudinal posterior da cabeça entre os lobos oculares superiores, toda extensão longitudinal central do pronoto entre os tubérculos látero-anteriores, e o escutelo.

Fronte plana, lisa, não-pontuada, com os lados ligeiramente divergentes para a região inferior. Lobos oculares superiores tão distantes entre si quanto a largura de um lobo. Tubérculos anteníferos não-projetados. Antenas com comprimento subigual ao do corpo; escapo e pedicelo robustos na base, pouco adelgaçados, revestidos por densa pubescência decumbente castanha; antenômero III mais longo que o escapo, com pubescência branca nos $3 / 4$ basais e intumescimento proeminente provido de pêlos; o IV, tão longo quanto o escapo, um pouco recurvado no meio e com pubescência branca na base, assim como os demais antenômeros; $\mathrm{V}-\mathrm{X}$ gradualmente decrescentes em comprimento; XI com metade do comprimento do X.

Protórax com tubérculo lateral cônico desenvolvido; calo centro-basal e tubérculos látero-anteriores do pronoto manifestos; élitros recobertos por densa pubescência castanhoclara e esbranquiçada mescladas, densamente granulados nos $2 / 3$ basais e com pontuação profunda no terço apical; gibosidade centro-basal pouco proeminente; espessamentos apicais e tufos de cerdas castanho-escuras discretos; protíbias discretamente aplanadas e dilatadas na metade apical; tarsos recobertos por densos pêlos esbranquiçados.

Urosternito V com discreta depressão na margem distal.

Dimensões (mm). Comprimento total, 12,1; comprimento do protórax, 2,0; maior largura do protórax, 3,9; comprimento do élitro, 8,2; largura umeral, 4,7 .

Material-tipo. Holótipo fêmea, COLÔMBIA, Santa Marta: Vista Nieva, 1920, F. M. Gaige col. (MNRJ).

Comentários. Assemelha-se a Phacellocerina limosa (Bates, 1862) pelo padrão de distribuição da faixa de pubescência esbranquiçada, revestindo a região longitudinal posterior da cabeça, entre os lobos oculares superiores, toda a extensão longitudinal central do pronoto, entre os tubérculos láteroanteriores, e todo o escutelo; pelas antenas das fêmeas com comprimento subigual ao do corpo. Distingue-se de $P$. limosa pela fronte lisa, não-pontuada; pelos lobos oculares superiores tão distantes entre si quanto a largura de um lobo; pelo escapo e pedicelo robustos na base, pouco adelgaçados e recobertos por densa pubescência decumbente; pelo intumescimento do antenômero III bastante desenvolvido e provido de pêlos; pela gibosidade centro-basal, espessamento e tufos de cerdas apicais dos élitros, discretos e pelo aspecto do urosternito $\mathrm{V}$ das fêmeas com discreta depressão na margem distal. Em P. limosa: fronte com pontuação profunda; lobos oculares superiores tão distantes entre si quanto o dobro da largura de um lobo; escapo e pedicelo adelgaçados na base e recobertos por máculas de pubescência decumbente rala; intumescimento do antenômero III discreto e sem pêlos; gibosidade centro-basal, espessamento e tufos de cerdas apicais dos élitros, proeminentes; urosternito $\mathrm{V}$ das fêmeas com depressão semi-circular centro-apical acentuada.

\section{Phacellocerina seclusa Lane, 1964}

Phacellocerina seclusa Lane, 1964:181; Monné, 1994:3 (cat.).

Foi examinado, apenas, o diapositivo do holótipo de $P$. seclusa, depositado no BMNH. Os caracteres arrolados na chave foram baseados na análise desse diapositivo.

Agradecimentos. Ao Dr. Miguel A. Monné (MNRJ) pelas sugestões e revisão do manuscrito; ao Dr. Renato C. Marinoni (DZUP) pelo empréstimo dos diapositivos; a Sérgio Barbosa Gonçalves pela execução das fotografias e à Fundação de Amparo à Pesquisa do Estado de São Paulo (FAPESP, Proc. $\mathrm{n}^{\circ}$ 98/10692-5) pela bolsa de Doutorado concedida.

\section{REFERÊNCIAS}

Bates, H.W. 1862. Contributions to an insect fauna of the Amazon Valley. Coleoptera. Longicornes. Annals and Magazine of Natural History 9(3): 446-458.

Galileo, M .H. M. \& U. R. Martins. 1998. Divisão do gênero Phacellocera (Coleoptera, Cerambycidae, Lamiinae, Anisocerini). Iheringia, Série Zoologia, (85): 11-25.

Lameere, A.A. 1893. Voyage de M.E. Simon au Venezuela (Decembre 1887-Avril 1888) 23e mémoire, longicornes. Annales de la Société Entomologique de France 62: 273-280.

LANE, F. 1964. Novos gêneros e espécies de Anisocerini (Coleoptera, Lamiidae). Studia Entomologica 7: 179-200.

Laporte, F. L. N. 1840. Histoire Naturelle des Insectes Coléoptères. Paris, Duménil, 2: 563 p., 36 pls.

Monné, M. A. 1994. Catalogue of the Cerambycidae (Coleoptera) of the Western Hemisphere. Part XVII. São Paulo, Sociedade Brasileira de Entomologia, 110 p.

Thomson, J. 1864. Systema cerambycidarum ou exposé de tous les genres compris dans la famille des cérambycides et familles limitrophes. Mémoires de la Société Royale des Sciences de Liège 19: 1540 . 